\begin{tabular}{ccc}
\hline International Journal of Engineering \& Technology, $7(4.33)(2018) 74-77$ \\
SPC & Website: www.sciencepubco.com/index.php/IJET \\
Research paper & International Journal of Engineering \& Technology \\
\hline
\end{tabular}

\title{
Measuring Anxiety Level of Failure Science Students in Performing Calculus Subject
}

\author{
J. A. Wahab*, N. F. Mohamad Razi, M. H. Mohammad Hamzah, A. Z. Azmi, N. H. Nasrudin \\ Faculty of Computer and Mathematical Sciences, Universiti Teknologi MARA (UiTM), Perak Branch, Tapah Campus, Tapah Road, \\ 35400 Perak, Malaysia \\ *Corresponding author E-mail: jufiz279@perak.uitm.edu.my
}

\begin{abstract}
Nowadays, mathematics has become an important subject in various fields. In UiTM Tapah Campus, Calculus is one of the compulsory subject must be taken by science student. However, majority of the students not enjoyable to enroll this subject and have negative thought that slowly becomes obstacle to them to graduate on time due to failure in this subject. Anxiety has been identified as the main reason among failure students. Thus, a set of questionnaire to measure anxiety level among them been constructed consists of three main section (General Information, Test Anxiety, Mathematics Anxiety) and been distributed through Google form in order to get the response from students. The data have been analyzed using IBM SPSS (V23). Several selection of data analysis method was used to answer the objectives for this study which are reliability test, descriptive statistics and ANOVA. Findings shows that student with lower grade (E or F) tended to have higher math and test anxiety compared to higher grade students (D and D+). Thus, lecturers can focus on the most affected students and give them the most exposure to mathematical activities. It also benefits university to achieve university target in Graduate on Time (GoT) students' percentage.
\end{abstract}

Keywords: Mathematics; Mathematics Anxiety; Test Anxiety; Graduate on Time (GoT)

\section{Introduction}

University students especially who are on science and technology tracks are compulsory to take mathematics or Calculus specifically during their early stages of study. However, most of them tend to fail the Calculus paper during their first semester. Several factors can be listed here such as culture shock due to transition from school life to university life, poor basic mathematics skills which inherit since their school life and many other factors. If they fail their first calculus subject for example Pre-Calculus, they are possibly will have a hard time with Calculus I, Calculus II and many other subjects which apply the basic knowledge of Calculus. Previous study had shown that there are four main factors which contribute to student failure during their school which are social factors, university related issues, psychological and health status [1]. Mathematics often considered as difficult subject, especially calculus for some students. As a result, there have been an increasing number of failure students who enroll in Pre-Calculus subject as they cannot perform in this subject. This will affect the number of graduate on time student as stated in university vision and mission. Previous study defines several factors causing this such as culture shock, poor basic Math skills and many other factors. Study has been proposed in order to determine the main failure factors of Pre-Calculus subject and to investigate the association between mathematics (SPM) and Pre-Calculus subject result. A cross-sectional study will be conducted focusing on the failure students from past semester that enrolled in Pre-Calculus subject. 90 students from Applied Science (AS120) programme who failed their Pre-Calculus subject from previous semester (September 2017 - January 2018) are selected due to their number of Graduate on Time (GOT) been affected due to mathematics subjects (Calculus subject). Mathematics is a very important subject in our education line especially in Malaysia.

In the development of the 11th Malaysia plan (RMK-11), the Graduate on Time (GoT) idea has been proposed by Ministry of Higher Education (MOHE) in 2016. Government at a point of view sees that with the increasing percentage of graduates who finish their study at a specific time, the cost of management of a university will be optimized [2]. In order to measure the effectiveness of GoT scheme, MOHE introduced a system named Intake Graduate on Time (iGoT). iGoT will measures the number of students at same cohort intake that graduates within the expected duration of their programme. In this sense, iGoT will make the university becomes more productive as the number of graduates produced increases [2].

Based on this, we come out with an idea to help faculty to identify whether all the listed factors are related to UiTM students especially to the repeaters. These will not only benefit our students itself, but to the faculty also in order to improve the Graduate on Time level.

\section{Literature Review}

Basic mathematics skills are very important for success in education line and in our life. Yet, people tend to have a negative feeling or fear when dealing with numerical information known as mathematics anxiety. Recently, many researchers are trying to identify the antecedents of mathematics anxiety, where they discover surprising factors, risk factors and also remedy. In general, most researchers agreed that Mathematics anxiety happen at the 
beginning of education line and become worse as the education gets higher and more challenging. This supports by [3] who address mathematics anxiety as a poor performance in mathematics. Anxiety involved some disturbing affect such as feeling, behavior and other real physical symptoms. In [4] described anxiety as a feeling of worry, nervousness or unease about certain event or something that cannot be ascertained. According to [5], mathematics anxiety happens when students take part in mathematics class, listening to lecture, working through mathematical problems and discussing mathematics. Student that not interested in mathematics can be recognized at kindergarten level, especially when they only had a poor achievement in mathematics but not in other subjects [6]. Some students did not experience take their childhood education seriously. They came to school, just to have fun with their friends or listening lightly to their teachers. When they are at home, they did not attempt to apply whatever they have learned during the day at school. This situation always becomes the factor of lacking of knowledge, especially in mathematics. Students who did not succeed in mastering basics knowledge such as reading, writing and calculating, they tend to not do well during their higher level of education. This situation indirectly will increase their level of anxiety [7] because mastering mathematics will lead students to involve a multi-tasking job [8] such as problem solving and computational skills.

There are many definition of mathematics anxiety based on previous study. In [9] define mathematics anxiety as negative emotional response that arises when challenged with mathematical task such as dividing, multiplication, fraction and many more. In [10] on the other hand supports by defining mathematics anxiety as feeling of tension and anxiety that interfere with the manipulation of numbers and the solving of any mathematical problems which arise in real life or academically. In addition, in [3] also stand on the definition of mathematics anxiety as emotional response towards mathematics. Overall, we can conclude that mathematics anxiety as a negative feeling about mathematics.

There are many instruments proposed by the researcher to measure the level of mathematics anxiety among students. One of the famous measurements of the mathematics anxiety level by [11], who state that mathematics anxiety, can be measured using a scale called the Mathematics Anxiety Rating Scale (MARS) proposed by [12]. MARS which then improved to Abbreviated Version of the Mathematics Anxiety Rating Scale (A-MARS) by [13] has 25 items measuring the level of anxiety based on four sections which are individual experience, test anxiety related issues, numerical tasks in day life and math course [9]. In our paper, our measurement is based on this model. However, there are many version of MARS had been introduced by some of the researcher based on their research field and requirements.

Further research suggests that mathematics anxiety symptoms can be cured among students. Once students start to understand that they are having symptoms of mathematics anxiety, they will be more prepared to face the problem. According to [3], prevention of development of mathematics anxiety is with an early identification of at-risk students by the teachers at low level of education will most likely the best solution. With the strong basic of mathematics, students had less problem of doing mathematics as their education getting higher. He also suggests that in order to weaken the link between mathematics anxiety and poor mathematics performance, the exposure to negative mathematics attitude must been avoid. During school task about mathematics, lecturer must create an environment where everybody is participating in solving mathematical problems. Participating will create experience and will reduce the negativeness feeling towards mathematics. On the other hand, he also proposed that students must have a positive thought when doing mathematics. These positive attitudes will create a positively minds, which will produce students with a positive aura.

\section{Methodology}

A cross-sectional study will be conducted focusing on the failure students from past semester that enrolled in Pre-Calculus subject. 90 students from Applied Sciences (AS120) programme that failed their Pre-Calculus subject from previous semester (September 2017-Jan 2018) are selected due to their number of Graduate on Time (GOT) been affected due to mathematics subjects (Calculus subject). A set of questionnaire consists of three main sections which are General Information, Test Anxiety and Mathematics Anxiety will be distributed through Google form in order to get the response from students. Google form being chosen as a medium to distribute the questionnaire because it is more friendly and easy for students to reach. 53 students out from 90 students response to the questionnaire. The data are then will be analyzed using IBM SPSS (Version 23). Several selection of data analysis method will be used in order to answer the objectives of this study which are reliability test, descriptive statistics and t-test.

\section{Results and Discussion}

\subsection{Reliability of the Data}

Table 1: Reliability test

\begin{tabular}{|c|c|c|}
\multicolumn{3}{|c|}{ Table 1: Reliability test } \\
\hline Latent Variable & Number of Items & Cronbach's Alpha \\
\hline Mathematics Anxiety & 10 & 0.762 \\
\hline Test Anxiety & 12 & 0.695 \\
\hline
\end{tabular}

Table 1 shows the reliability test of the two subscales named as Mathematics Anxiety and Test Anxiety. A Cronbach's alpha is somehow a correlation coefficient of the scale with itself - you have to set thresholds for what is acceptable and not. From the result, it is shows that the Mathematics Anxiety subscale consisted of 10 items $(\alpha=0.762)$ and the Test Anxiety subscale consisted of 12 items $(\alpha=0.695)$. As a whole, Mathematics Anxiety and Test Anxiety can be acceptable subscale to be used in this study since it ranging between $0.5-0.8$ values [14].

\subsection{Exploring Data}

Table 2: Summaries of variables

\begin{tabular}{|c|c|c|c|}
\hline Table 2: Summaries of variables \\
\cline { 2 - 4 } & Level of Variable & \multicolumn{2}{|c|}{ Result MAT133 } \\
\cline { 2 - 4 } & & D or D+ & E or F \\
\hline \multirow{2}{*}{ Variables } & Male & 7 & 5 \\
\cline { 2 - 4 } & Female & 19 & 22 \\
\hline \multirow{2}{*}{ Like Mathematics } & No & 15 & 18 \\
\cline { 2 - 4 } & Yes & 11 & 9 \\
\hline \multirow{2}{*}{ SPM Result } & Credit & 0 & 1 \\
\cline { 2 - 4 } & Pass & 1 & 1 \\
\cline { 2 - 4 } & Fail & & 25 \\
\hline
\end{tabular}

Based on the output in Table 2, it explains that male students tend to response less than female students. Other than that, it also found that $62.3 \%$ of these failure students did not likes mathematics subject and failed in MAT 133 course. Furthermore, result shows that for about $94.3 \%$ of the failure students has earned credit grade (A, B and C), $1.9 \%$ earned Pass (D or E) and only 3.8\% failure student who failed during SPM result.

\subsection{The effect of MAT133 result on Mathematics Anxie- ty and Test Anxiety}

\subsubsection{Checking for Outliers}



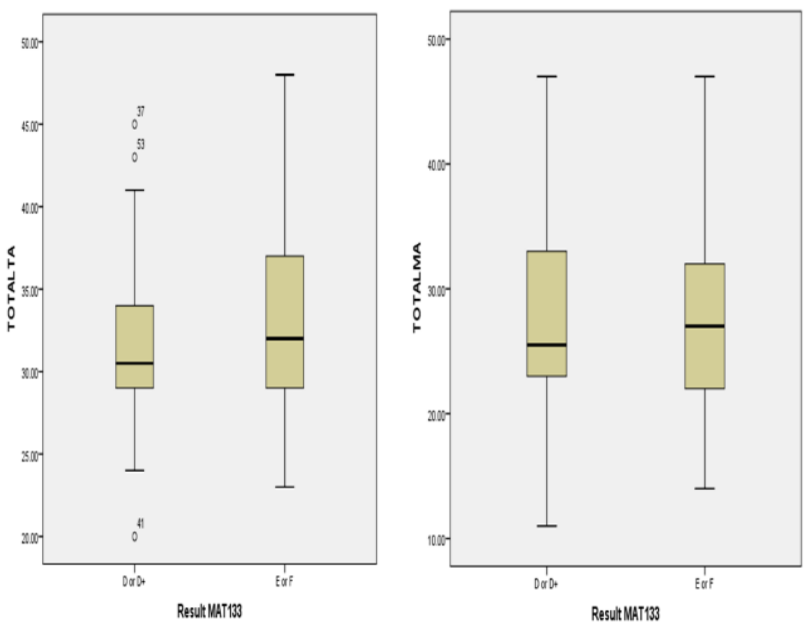

Fig. 1: Box plot for Test Anxiety and Math Anxiety

Figure 1 shows that the boxplot analysis in order to explore, whether there is/are existence of significant outliers that believed that could negatively influence the results if this study. The test shows that for Mathematics Anxiety score, there is outliers identified. Meanwhile, for Test Anxiety score, it found that there are several outliers. However, further analysis can still be proceeded since the outliers is not influence much on the data distribution.

\subsubsection{Checking the Normality of the Data for Each of the MAT133 Result}

Table 3: Normality Test for each of the level in MAT133 result

\begin{tabular}{|c|c|c|c|c|}
\hline & Shapiro Wilk & Sig. \\
\hline \multirow{2}{*}{$\begin{array}{l}\text { Test Anxie- } \\
\text { ty Score }\end{array}$} & \multirow[t]{2}{*}{ MAT133_result } & D or D+ & 0.962 & 0.435 \\
\hline & & $\mathrm{E}$ or $\mathrm{F}$ & 0.926 & 0.145 \\
\hline \multirow{2}{*}{$\begin{array}{c}\text { Mathematics } \\
\text { Anxiety } \\
\text { Score }\end{array}$} & \multirow{2}{*}{ MAT133_result } & D or D+ & 0.962 & 0.435 \\
\hline & & $E$ or $F$ & 0.926 & 0.145 \\
\hline
\end{tabular}

Table 3 explains about the normality of the data. By holding the null hypothesis indicated that these data are normally distributed, this study does not have enough evidence to reject $\mathrm{H}_{0}$ for both variables (Test Anxiety and Mathematics Anxiety scores) as the significance values $>0.05$. Thus, this study has not violated the normality of the data.

\subsubsection{Check That There is Homogeneity of Variances}

Table 4: Test of homogeneity of Variances

\begin{tabular}{|c|c|c|c|c|}
\hline Anxiety Score & Levene Statistics, F & df1 & df2 & Sig. \\
\hline Test Anxiety Score & 0.720 & 1 & 51 & 0.400 \\
\hline $\begin{array}{c}\text { Mathematics Anxiety } \\
\text { Score }\end{array}$ & 0.195 & 1 & 51 & 0.661 \\
\hline
\end{tabular}

Table 4 shows the test of homogeneity of variances for Test Anxiety score and Mathematics Anxiety score. Based on the result, Test Anxiety score $(\mathrm{F} 1,51=0.720$, sig. $>0.05)$ and Mathematics Anxiety score $(\mathrm{F} 1,51=0.195$, sig. $>0.05)$. This indicated that the result has not violated the homogeneity of variance assumption.

\subsubsection{Testing the Significance Difference of Mathematics Anx- iety and Test Anxiety toward MAT133 Result}

The descriptive statistics in Table 5 and Table 6 explains some useful descriptive statistics, such as mean and standard deviation for the Mathematics Anxiety score (Table 5) and Test Anxiety (Table 6) for each MAT133 grade results (D or D+ and E or F). 26 students had an average Mathematics Anxiety score of 27.6923 $(\mathrm{SD}=7.984)$ and another 27 students had a Mathematics Anxiety score of $28.185(\mathrm{SD}=8.51)$. In addition, Table 6 , revealed that 26 students had an average Test Anxiety score of 31.5769 (SD =
5.90) and another 27 students had a Test Anxiety score of 33.4815 $(\mathrm{SD}=6.85)$. This shows that students obtained $\mathrm{E}$ or F in MAT 133 tend to have high Mathematics Anxiety compare to students who obtained $\mathrm{D}$ or $\mathrm{D}+$. This means that students obtained $\mathrm{E}$ or $\mathrm{F}$ in MAT133 tend to have high Mathematics and Test Anxiety compare to students who obtained D or D+.

Table 5: Descriptive Statistics for Mathematics Anxiety

\begin{tabular}{|c|c|c|c|}
\hline MAT133 Result & N & Mean & Std. Deviation \\
\hline D or D+ & 26 & 27.6923 & 7.9838 \\
\hline E or F & 27 & 28.1852 & 8.5081 \\
\hline Total & 53 & 27.9434 & 8.1793 \\
\hline
\end{tabular}

Table 6: Descriptive Statistics for Test Anxiety

\begin{tabular}{|c|c|c|c|}
\hline MAT133 Result & $\mathrm{N}$ & Mean & Std. Deviation \\
\hline D or D+ & 26 & 31.5769 & 5.9003 \\
\hline E or F & 27 & 33.4815 & 6.8577 \\
\hline Total & 53 & 32.5472 & 6.4168 \\
\hline
\end{tabular}

Thus, one-way between subject ANOVA was conducted to compare the difference of Mathematics and Test Anxiety on MAT133 grade (D or $\mathrm{D}+$ ) and (E or F). The result shows that Mathematics Anxiety (Table 7) score does not significantly difference on MAT133 result at the $p<0.05$ level $(F 1,51=0.047, p=0.829>\alpha$ $=0.05]$. Besides, Test Anxiety in Table 7 also found to be insignificant different on MAT133 grade $(\mathrm{F} 1,51=1.171, \mathrm{p}=0.284>\alpha$ $=0.05$ ).

Table 7: ANOVA test

Table 7: ANOVA test
\begin{tabular}{|c|c|c|c|}
\hline Anxiety Score & df & F & Sig. \\
\hline Model 1:Mathematics Anxiety & 1,51 & 0.047 & 0.829 \\
\hline Model 2:Test Anxiety & 1,51 & 1.171 & 0.284 \\
\hline
\end{tabular}

\section{Conclusion}

This study has informed us of the factor of mathematics failure among students. The indicated result shows that there was no difference in mathematics anxiety and test anxiety according to MAT133 grade result among science students in UiTM Tapah Campus. This support finding in previous study where there is a relationship between mathematics and test anxiety, but at a low level. In addition, our research shows that student with lower grade (E or F) tended to have higher math and test anxiety compared to higher grade students ( $D$ and $D+$ ). In view of this, we can say that basic knowledge is very important as recommended in previous research: in order to reduce mathematics anxiety, teachers as early as kindergarten level must identify students who had the most problem in mathematics and give them the most exposure to mathematical activities.

In conclusion, the main reason of failure among UiTM Tapah Campus students in Pre-Calculus is due to their level of mathematics and test anxiety, which affected by their poor performance in mathematics which are not begin at university level, it happens since their school level. It is recommended that students who experience with anxiety be determined to facilitate the organization to find a solution. There are varieties proven techniques and activities that can be implemented to overcome mathematics anxiety. UiTM Tapah Campus also suggested organizing a continuous workshop that exposes the student toward mathematical exercises. In our research, we only focused on two small factors contributing to failure in mathematics. However, for further research, it is much recommended for researcher to look into a bigger scope of study whereby they can distribute the questionnaire to every student in the respected university. On the other hand, some other factors such as human factors, health problem, university equipment and many more can be included in our further research. 


\section{Acknowledgement}

The authors cordially acknowledge the significant contribution and financial support provided by Universiti Teknologi MARA Perak Branch in the production of this paper.

\section{References}

[1] Kamal, M., \& Bener, A. (2009). Factors contributing to school failure among school children in very fast developing Arabian Society. Oman Medical Journal 24(3), 212-217.

[2] Kementerian Pendidikan Tinggi Malaysia. (2015). Enhancing university board governance and effectiveness: University transformation programme green book. Kementerian Pendidikan Tinggi Malaysia.

[3] Erin, A. M., \& Sian, L. B. (2012). Math anxiety: Who has it, why it develops, and how to guard against it. Trends in Cognitive Sciences 16(8), 404-406.

[4] Dorothy, E. A., Edith, N. N., Joachim, C. O., \& Uchenna, N. E., (2015). Influence of socio-economic status and classroom climate on mathematics anxiety of primary school pupils. Procedia - Social and Behavioral Sciences, 205, 693-701.

[5] Sarah, R. (2006). Overcoming math anxiety. Mathitudes 1(1), 1-4.

[6] David, W. (1988). Special needs in ordinary schools: Developing mathematical and scientific thinking in young children. Mackays of Catham PLC.

[7] Nur Azlina, A. A., Ku Fauziah, K. B., \& Angelina, R. V. (2010). Mathematics anxiety amongst the malays students: A case study in UiTM Melaka. Universiti Teknologi MARA.

[8] Sahin, K., \& Ahmet, R. (2010). Mathematics anxiety according to the middle school students' achievement motivation and social comparison. Education Journal 131(1), 54-63.

[9] Alyssa, R. G. D. H., Joseph, M. F., María, D. V. C., \& John, D. M. (2017). Pre-service elementary teachers' achievement goals and their relationship to math anxiety. Learning and Individual Differences 60, 40-45.

[10] Frieder, L. S., Stephan, E. V., Jennifer, D., \& Roland, H. G. (2018). Math anxiety, intelligence, and performance in mathematics: Insights from the German adaptation of the Abbreviated Math Anxiety Scale (AMAS-G). Learning and Individual Differences 61 , 109-119.

[11] Laura, I. (2007). Strategies for reducing math anxiety in postsecondary students. Proceedings of the Sixth Annual College of Education Research Conference, pp. 30-35.

[1] Richardson, F. C., \& Suinn, R. M. (1972). The mathematics anxiety rating scale: Psychometric data. Journal of Counselling Psychology 19(6), 551-554.

[2] Elizabeth, F., \& Penelope, L. P. (1986). Teacher-student interactions and sex-related differences in learning mathematics. Teaching and Teacher Education 2(1), 19-42.

[3] Nunnally, J. C., \& Bernstein, I. H. (1994). Psychometric theory. McGraw-Hill. 